\title{
Editorial
}

Rupsa C. Boelig* and Vincenzo Berghella

\section{What's new in preterm birth prediction and prevention?}

https://doi.org/10.1515/jpm-2018-0160

Preterm birth is a leading cause of neonatal morbidity and mortality. The United States preterm birth rate rose to $9.85 \%$ in 2016 , a $2 \%$ rise from 2015 . This the second consecutive year that the preterm birth rate has risen; it had been declining steadily from 2007 to 2014. This issue of Journal of Perinatal Medicine explores a wide range of topics related to preterm birth prediction and prevention from basic and translational sciences, to clinical interventions and management, to epidemiology and outcomes.

\section{Basic and translational science}

Latino et al. [1] explore a new promising area of research in preterm birth prediction - vaginal microbiome. Their unique study looks at both placental histology and fetal tracheobronchial aspirates for the detection of genital mycoplasma. They identified a strong link between specific mycoplasmas and histologic chorioamnionitis in spontaneous abortion, highlighting an important area for exploration in the link between vaginal microbiome pregnancy outcomes.

Bhavnani et al. [2] used a unique study method to identify methylation differences in subgroups of preterm birth pathophysiology. Their results notably found patient subgroups based on methylation differences alone, providing a potential pathway for identifying preterm birth subtypes. This work builds on our understanding of epigenetic differences that may elucidate pathways to preterm birth and provide targets for intervention.

Staps et al. [3] use the rare condition of Sjogren-Larsson syndrome, which exhibits a high rate of preterm birth, to better understand how biologically active lipids may contribute to preterm birth pathways in the fetus. By studying this naturally created environment of fetal lipid accumulation,

\footnotetext{
*Corresponding author: Rupsa C. Boelig, MD, Thomas Jefferson University Hospitals, Division of Maternal Fetal Medicine, Philadelphia, PA, USA, E-mail: rupsa.c@gmail.com Vincenzo Berghella: Jefferson Medical College of Thomas Jefferson University, Department of Obstetrics and Gynecology, Philadelphia, PA, USA
}

they are able to theorize on fetal pathways contributing to preterm birth.

\section{Clinical interventions and management}

Daskalakis et al. [4] present a prospective study on the safety and efficacy of cervical pessary and vaginal progesterone for preterm birth prevention in women with a short cervix. They identify that this combination of preterm birth interventions is safe, well tolerated, and led to pregnancy prolongation of about 13.5 weeks. The results of this cohort study certainly warrant further randomized study comparing the combination of pessary and vaginal progesterone to either alone; such trials are currently underway (NCT02901626, NCT03052270).

Tchirikov et al. [5] present a thorough review of the etiology, diagnosis, management and outcomes of the clinically challenging condition of mid-trimester preterm premature rupture of membranes (PPROM). The review includes new Food and Drug Administration (FDA) approved tools in diagnosis such as detection of placental alpha macroglobulin 1 (PAMG-1) utilized by Amnisure, an outline of international guidelines in expectant management of PPROM, and experimental approaches in management such as fetal membrane repair and continuous amnioinfusion.

\section{Epidemiology and outcomes}

Baer et al. [6] examine the risk of preterm birth in a second pregnancy. This large cohort study included over 2 million women. Notably they found that even among women with a term delivery, the odds of delivering a second pregnancy preterm differed by race and age, with Hispanic, Black and Asian non-Hispanic women $<18$ years for both pregnancies at higher odds of having a subsequent preterm birth. Asian non-Hispanic women $>34$ years for both pregnancies were also at higher risk of a subsequent preterm birth following a term delivery. Confirming what is known, they 
found that women with an initial preterm birth were 3-7 times more likely to have a preterm birth in their second pregnancy. This large cohort study identifies important risk factors for preterm birth in a population historically considered "low risk", those with a prior full term delivery.

Premru-Srsen et al. [7] conducted a large population based cohort study over 10 years of over 200,000 singleton, non-anomalous, live births in Slovenia. They identified that birthweight for gestational age is significantly associated with infant mortality only in infants born at term. This large cohort study makes two important points, first that gestational age rather than birthweight is a driving factor in neonatal outcomes of preterm deliveries, and second that term infants that are small for gestational age are at significantly higher risk of infant mortality compared to their appropriate for gestational age peers.

Kiver et al. [8] present an important study of perinatal outcomes in the setting of previable PPROM ( $<24$ weeks). This is a medically and often ethically difficult scenario to manage, and having concrete data on risks and outcomes is crucial to patient counseling. They present a review of 73 patients with 93 fetuses hospitalized with previable PPROM. This study includes singletons and multiples. They highlight some interesting results including the median GA of previable PPROM in singletons and multiples that results in a live birth versus spontaneous miscarriage. Additionally, a particularly useful outcome in counseling, they report on outcomes by gestational age of diagnosis. As with all studies of this nature there is an inherent bias in reporting incidence of poor outcomes due to an exclusion of pregnancies that were terminated, nonetheless this study adds to the literature on outcomes of this precarious condition and will assist in counseling patients.

Obladen [9] presents in his review at the beginning of this issue a unique look at the history of our understanding of fetal respiration. He reviews the historical progression in the understanding of fetal/placental circulation. The early understanding, and misunderstandings, of fetal circulation in the 1500s-1700s are truly remarkable given the limited modes of study available, and our continued limited understanding of placental function highlights how far we have yet to go in unraveling this mystery. This piece is not only interesting, but timely, given we are at an age where artificial placentas are being developed.

\section{References}

[1] Latino MA, Botta G, Badino C, De Maria D, Petrozziello A, Sensini A, et al. Association between genital mycoplasmas, acute chorioamnionitis and fetal pneumonia in spontaneous abortions. J Perinat Med. 2018;46:503-8.

[2] Bhavnani SK, Dang B, Kilaru V, Caro M, Visweswaran S, Saade G, et al. Methylation differences reveal heterogeneity in preterm pathophysiology: results from bipartite network analyses. J Perinat Med. 2018;46:509-21.

[3] Staps P, Hogeveen M, Fuijkschot J, van Drongelen J, Willemsen MAAP. Understanding fetal factors that contribute to preterm birth: Sjögren-Larsson syndrome as a model. J Perinat Med. 2018;46:523-9.

[4] Daskalakis G, Zacharakis D, Theodora M, Antsaklis P, Papantoniou N, Loutradis D, et al. Safety and efficacy of the cervical pessary combined with vaginal progesterone for the prevention of spontaneous preterm birth. J Perinat Med. 2018;46:531-7.

[5] Tchirikov M, Schlabritz-Loutsevitch N, Maher J, Buchmann J, Naberezhnev Y, Winarno AS, et al. Mid-trimester preterm premature rupture of membranes (PPROM): etiology, diagnosis, classification, international recommendations of treatment options and outcome. J Perinat Med. 2018;46:465-88.

[6] Baer RJ, Yang J, Berghella V, Chambers CD, Coker TR, Kuppermann $M$, et al. Risk of preterm birth by maternal age at first and second pregnancy and race/ethnicity. J Perinat Med. 2018;46:539-46.

[7] Premru-Srsen T, Verdenik I, Ponikvar BM, Steblovnik L, Geršak K, Cerar LK. Infant mortality and causes of death by birth weight for gestational age in non-malformed singleton infants: a 2002-2012 population-based study. J Perinat Med. 2018;46:547-53.

[8] Kiver V, Boos V, Thomas A, Henrich W, Weichert A. Perinatal outcomes after previable preterm premature rupture of membranes before 24 weeks of gestation. J Perinat Med. 2018;46:555-65.

[9] Obladen M. Pulmo uterinus: a history of ideas on fetal respiration. J Perinat Med. 2018;46:457-64. 